\title{
Emprego do compósito látex, poliamida e polilisina a 0,1\% na correção cirúrgica de hérnias umbilicais recidivantes em bovinos leiteiros
}

\author{
Use of the polilisine $0.1 \%$ and poliamide, latex membrane in the \\ surgical correction of recidivating umbilical hernias in dairy cattle \\ Rogério Elias Rabelo', Fabiano José Ferreira de Sant'Ana', Neusa Margarida Paulo², Alana Flávia \\ Romani ${ }^{1}$, Luiz Antônio Franco da Silva ${ }^{2}$, Marco Antônio de Oliveira Viu ${ }^{1}$, Cláudia Bueno Alves ${ }^{3}$, \\ Caroline Rocha de Oliveira Lima ${ }^{4} \&$ Olízio Claudino da Silva²
}

\begin{abstract}
RESUMO
Implantes biológicos e sintéticos têm sido comumente utilizados em cirurgia experimental com resultados promissores. Esse trabalho tem por objetivo avaliar a viabilidade do compósito de látex, poliamida e polilisina a $0,1 \%$ como implante nas hernioplastias umbilicais recidivantes. Utilizou-se 12 bovinos, mestiços e machos (idade 8-10m). As hernioplastias foram efetuadas com a justaposição do compósito sob o anel herniário. Efetuou-se avaliações clínicas diárias, por meio de escores, como segue: processo inflamatório (0-3), deiscência da ferida cirúrgica (0-2), além de abscessos, fistulações e recidiva (0-1, cada). Realizou-se avaliação macroscópica do sítio de implantação e colheita de material para histopatologia em dois animais aos 15 dias, dois aos 30 dias e dois aos 45 dias após o implante. Aos 10 dias de pós-operatório, observou-se processo inflamatório de escore 1 nos doze animais. Constatou-se após a biópsia, processo inflamatório de escore 3 nos seis animais e deiscência da ferida cirúrgica com escore 1 em quatro bovinos e escore $2 \mathrm{em}$ dois animais. Verificou-se intensa associação entre o tecido conjuntivo neoformado e o tecido muscular, promovendo estabilidade e reparação cicatricial. No $15^{\circ}$ dia observou-se fibroblastos associados à neovascularização e infiltrado de macrófagos, linfócitos e plasmócitos. Afastando-se da área de implante, havia predominância de colágeno. No $30^{\circ}$ dia, notou-se feixes conjuntivos, discreta neovascularização e infiltrado de macrófagos. No $40^{\circ}$ dia notaram-se características microscópicas semelhantes às observadas aos 30 dias. Conclui-se que o compósito de látex, poliamida e polilisina a $0,1 \%$ é eficaz nas hernioplastias umbilicais em bovinos.
\end{abstract}

Descritores: hérnia umbilical recidivante, implante, bovino.

\section{ABSTRACT}

Biologic and synthetic implants has been utilized frequently in experimental surgery with promising results. This work aims to value the utilization of the $0.1 \%$ polylisin and poliamide, latex membrane as graft in the recidivanting umbilical hernioplasty in cattle. Twelve crossbred, male, bovines (8-10 months) were used in the study. The herniopalstys were realized with the juxtaposition of the membrane over the hernial ring. Diary clinic valuations were performed through scores. Inflammatory process (0-3), wound dehiscence (0-2), abscess (0-1), fistula (0-1) and recidivation (0-1) were considered. Macroscopic evaluation of the implant local and samples collection to histopathological examination were realized in two animals on 15, two on 30 and two on 45 days post-surgery. Inflammatory process with score 1 was observed in all animals on 10 day. After biopsy, it was noted inflammatory process of score 3 in six bovines, wound dehiscence with score 1 in four animals and with score 2 in two bovines. Young conjunctive and muscular tissues were intensily associated, promoting stability and cicatricial repair. In the 15th day, angiogenesis were observed associated to the fibroblasts and infiltration of macrophages, lymphocytes and plasma cells. There was predominance of collagen in the periphery of the lesion. In the 30th day, it was noted conjunctive bunches, discrete angiogenesis and infiltration of macrophages. In the 40th day, it were observed similar microscopic characteristics to noted in 30 th day. It was conclued that the $0.1 \%$ polylisin and poliamide, latex membrane is efficacious in the umbilical hernioplasty in cattle.

Key words: recidivating umbilical hernia, implant, bovine. 


\section{INTRODUÇÃO}

As hérnias umbilicais são freqüentemente observadas em bovinos jovens, podendo afetar até $10 \%$ dos recém-nascidos [3]. A enfermidade pode apresentar origem genética ou adquirida e diminui o valor comercial dos animais, podendo levá-los ao óbito, acarretando aumento nos custos de produção e prejuízos econômicos ao criatório.

Diversos estudos experimentais têm sido desenvolvidos a fim de se implementar novas técnicas na correção das hérnias umbilicais em bovinos, principalmente, quando não há possibilidade de empregar a herniorrafia tradicional, devido à falta de tecido íntegro para promover a aproximação das estruturas e o conseqüente fechamento do anel herniário. Neste contexto, a utilização de implantes tem sido comumente empregada, com resultados promissores [22].

Em consequiência da ausência de métodos ideais, os compósitos, como as membranas de látex natural, poliamida e polilisina a $0,1 \%$, vêm se mostrando uma boa alternativa em cirurgias experimentais. Sua utilização foi descrita no reparo de lesões esofágicas em cães com resultados animadores [8]. O material não é incorporado pelo hospedeiro, servindo somente como ponte para a regeneração tecidual. Esta observação, aliada a sua resistência física e boa tolerância por parte do receptor permitiram que se iniciassem investigações para sua possível utilização como implante [8].

Este trabalho teve como objetivo avaliar, utilizando parâmetros clínicos e histopatológicos, a viabilidade da membrana de látex, poliamida e polilisina a $0,1 \%$ como material de implante na correção cirúrgica de hérnias umbilicais recidivantes em bovinos leiteiros.

\section{MATERIAIS E MÉTODOS}

Foram utilizados doze bovinos machos, mestiços (Bos taurus taurus x Bos taurus indicus), com idade entre oito a dez meses, portadores de hérnias umbilicais recidivantes, cujo diâmetro longitudinal do anel herniário fosse de, no mínimo, dez centímetros, e o transversal, de sete centímetros.

Todos os procedimentos cirúrgicos, bem como as avaliações pós-operatórias foram realizados na Fazenda Escola do Campus de Jataí da Universidade Federal de Goiás. A membrana de látex, poliamida e polilisina a $0,1 \%$ foi confeccionada artesanalmente no Departamento de Bioquímica da Faculdade de Medi- cina de Ribeirão Preto da Universidade de São Paulo, a partir da seiva da Hevea brasiliensis [19].

Os bovinos foram submetidos à jejum hídrico e alimentar de 24 horas previamente ao ato cirúrgico. A medicação pré-anestésica consistiu da administração de cloridrato de xilazina ${ }^{1}$ a $2 \%$ na dosagem de $0,1 \mathrm{mg} / \mathrm{kg}$. Os animais foram contidos em decúbito dorsal em mesa adaptada para a execução do procedimento. Após a tricotomia e lavagem com água e sabão, realizou-se antissepsia e a anestesia local infiltrati$\mathrm{va}$, circundando a base do saco herniário com cloridrato de lidocaína ${ }^{2}$ a $2 \%$.

Realizou-se incisão elíptica na pele, tendo como ponto de referência a linha alba, anterior e posterior ao saco herniário. Em seguida, efetuou-se a divulsão tecidual para a remoção das fibroses presentes [20]. Posteriormente foi realizada a abertura do saco herniário e medição do diâmetro do anel, por meio de paquímetro.

Para efetuar a justaposição da membrana de látex poliamida e polilisina a $0,1 \%$ sob o anel herniário, foram aplicados seis pontos tipo Donatti, abrangendo o peritôneo e à bainha externa do músculo reto abdominal ou em áreas adjacentes ao anel quando tal estrutura encontrava-se comprometida (Figura 1). Para a execução destes pontos, foram empregados fios de poliamida $\mathrm{n}^{\circ} 1$ encastoado de fábrica com agulha cilíndrica semicircular. Objetivando melhor fixação do implante à fáscia abdominal externa, realizou-se adicionalmente sutura em padrão simples contínua com o mesmo tipo de fio. Posteriormente, reduziu-se o espaço morto com fio orgânico absorvível $n^{\circ} 1$. Após essa manobra, foi efetuada dermorrafia, em padrão simples interrompido com fio de poliamida $\mathrm{n}^{\circ} 1$.

No pós-operatório os animais foram mantidos em piquetes de Brachiaria decumbens, recebendo água e como medida preventiva adotou-se o corte da gramínea na altura de $30 \mathrm{~cm}$, a fim de evitar traumas na ferida cirúrgica. Realizou-se antibioticoterapia parenteral com uma associação de benzilpenicilina procaína, sulfato de diidroestreptomicina, piroxicam micronizado e cloridrato de procaína ${ }^{3}$ na dosagem de $40.000 \mathrm{UI} / \mathrm{Kg}$ de peso corporal por via intramuscular, em intervalos de 24 horas, perfazendo cinco aplicações. Adicionalmente, foram feitos curativos locais diários com pomada à base de sulfanilamida, trichlorphon, óxido de zinco, óleo de pinho e vitamina $\mathrm{A}^{4}$. Os pontos da pele foram removidos no $15^{\circ}$ dia de pós-operatório.

Todos os animais do estudo foram avaliados diariamente, utilizando métodos semiológicos de rotina [15]. 
Visando facilitar a avaliação clínica foram estabelecidos escores [13], para determinar a intensidade do processo inflamatório: (0) ausência de inflamação; (1) sensibilidade à palpação, edema e hiperemia discretos; (2) sensibilidade à palpação, edema e hiperemia moderados; (3) sensibilidade à palpação, edema e hiperemia graves. Quanto a deiscência da ferida cirúrgica atribuiu-se: (0) ausência; (1) deiscência inferior a 50\% da extensão da incisão cirúrgica; (2) deiscência superior a 50\% e inferior a 100\%; (3) deiscência completa da incisão cirúrgica. Quanto aos abscessos, fistulações e recidiva da enfermidade, considerou-se: (0) ausente e (1) presente.

A fim de avaliar o comportamento e a integração do material no sítio do implante realizou-se a avaliação macroscópica e colheita de material para histopatologia em seis animais, sorteados aleatoriamente. As amostras coletadas compreendiam as bordas do implante e os tecidos circunvizinhos. Os espécimes clínicos foram obtidos de dois animais aos 15 dias, de dois animais aos 30 dias e de dois animais aos 45 dias após a intervenção cirúrgica. Os fragmentos mediam aproximadamente $2 \times 1 \times 0,5 \mathrm{~cm}$ e foram fixados por $24 \mathrm{~h} \mathrm{em}$ formol neutro e tamponado a $10 \%$, sendo acondicionados em recipientes individuais, previamente identificados. Em seguida, os tecidos foram processados rotineiramente para avaliação histopatológica, incluídos em parafina e corados pela hematoxilina-eosina (HE) [11].

\section{RESULTADOS}

Até o $15^{\circ}$ dia de avaliação pós-operatória, nenhum dos animais submetidos à implantação apresen- tou graves complicações, de acordo com os escores de avaliação previamente definidos. Todavia, observou-se em todos os animais do estudo, nos primeiros cinco dias após a intervenção cirúrgica, processo inflamatório de escore 1, sendo facilmente contornado com duchas locais de água fria durante dez minutos diariamente.

Constatou-se, nos animais submetidos à colheita de material para histopatologia processo inflamatório de escore 3 no seis animais e deiscência da ferida cirúrgica com escore 1 em quatro bovinos e com escore 2 em dois animais. Todas as complicações observadas após as biópsias ocorreram, em média, dez dias após a realização da mesma, independente do período da colheita. Nos outros seis indivíduos, nos quais não foram realizadas biópsias pós-implantação, obteve-se escore 0 (zero) para os parâmetros de deiscência de ferida, abscessos, fístulas ou recidivas, até a cicatrização clínica completa, que ocorreu, em média, aos 22 dias de pós-operatório. Os achados clínicos relacionados as complicações pós-cirúrgicas encontram-se resumidas no Quadro 1.

No momento da colheita de material para histopatologia, observou-se que a membrana compósita implantada mantinha seu formato original, não havendo retração ou enrugamento da mesma. Nesta ocasião, foi notado crescimento acentuado de tecido conjuntivo fibroso sobre a membrana de látex, poliamida e polilisina a $0,1 \%$. Macroscopicamente, havia associação intensa entre o tecido conjuntivo neoformado e o tecido muscular adjacente, promovendo assim, adequada estabilidade e reparação cicatricial.

Quadro 1. Alterações clínicas observadas no pós-operatório de bovinos leiteiros após hernioplastia umbilical utilizando
membrana de látex poliamida e polilisina a 0,1\%, submetidos ou não à colheita de material para histopatologia, na Uni-
versidade Federal de Goiás - Campus Avançado de Jataí, 2004.
\begin{tabular}{|c|c|c|c|c|c|c|}
\hline \multirow{2}{*}{ No do animal $^{\text {Colheita para }}$} & $\begin{array}{c}\text { Processo } \\
\text { histopatologia }\end{array}$ & $\begin{array}{c}\text { Deiscência (0-3) } \\
\text { inflamatório (0-3) }\end{array}$ & Abscesso (0-1) & Fístula (0-1) & Recidiva (0-1) \\
\hline 1 & Sim & 3 & 2 & 0 & 0 & 0 \\
\hline 2 & $\operatorname{Sim}$ & 3 & 1 & 0 & 0 & 0 \\
\hline 3 & $\operatorname{Sim}$ & 3 & 1 & 0 & 0 & 0 \\
\hline 4 & $\operatorname{Sim}$ & 3 & 2 & 0 & 0 & 0 \\
\hline 5 & $\operatorname{Sim}$ & 3 & 1 & 0 & 0 & 0 \\
\hline 6 & $\operatorname{Sim}$ & 3 & 1 & 0 & 0 & 0 \\
\hline 7 & Não & 1 & 0 & 0 & 0 & 0 \\
\hline 8 & Não & 1 & 0 & 0 & 0 & 0 \\
\hline 10 & Não & 1 & 0 & 0 & 0 & 0 \\
\hline 11 & Não & 1 & 0 & 0 & 0 & 0 \\
\hline 12 & Não & 1 & 0 & 0 & 0 & 0 \\
\hline
\end{tabular}




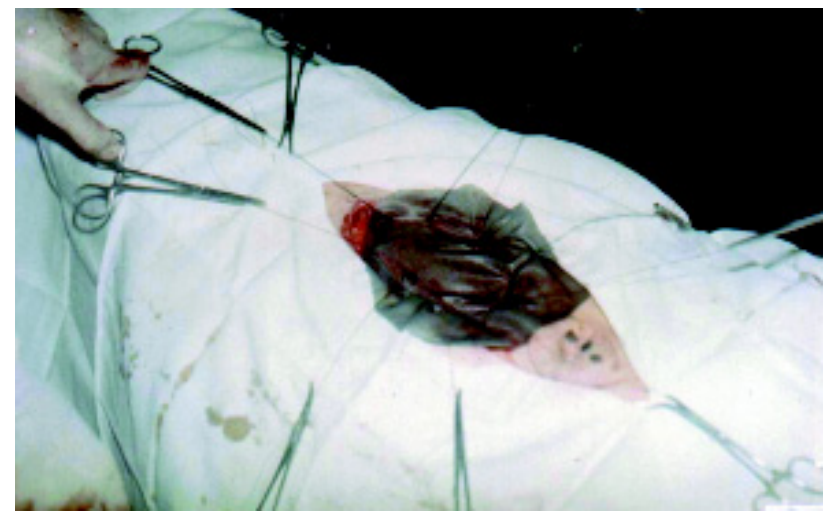

Figura 1. Justaposição do material compósito sob o anel herniário utilizando seis pontos tipo Donatti.
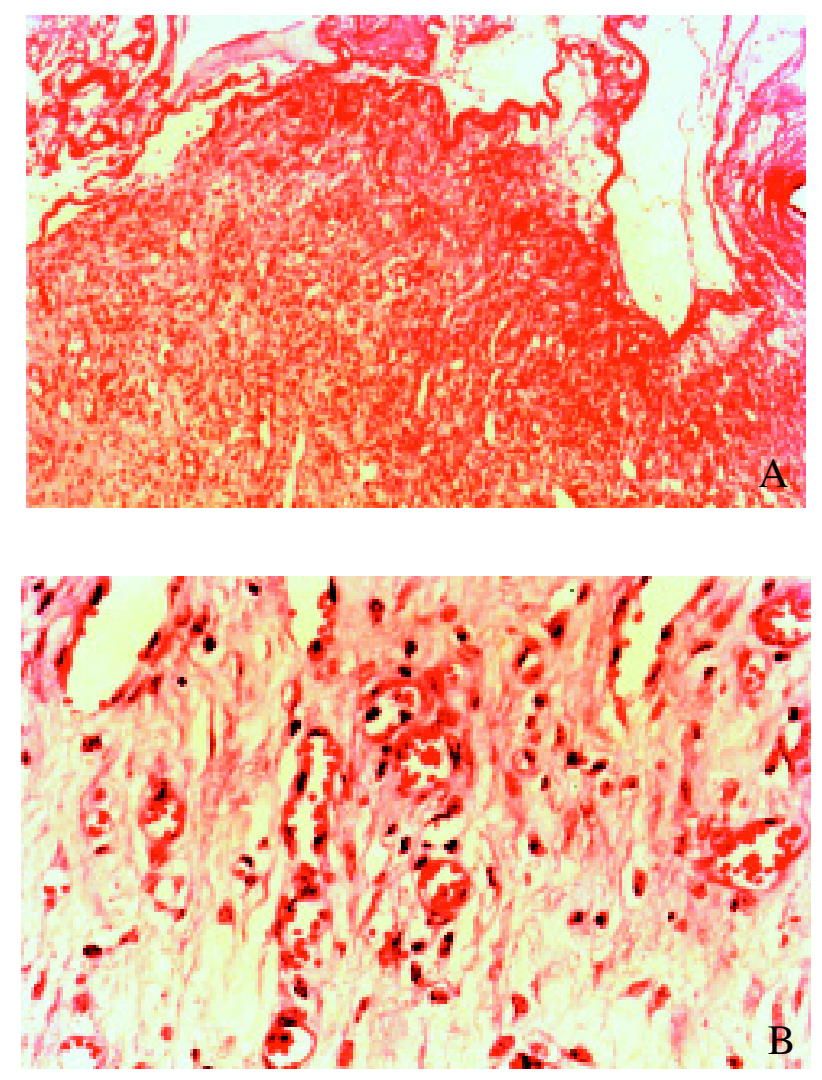

Figura 2. A - Corte histológico da área de implante no $15^{\circ}$ dia demonstrando infiltrado inflamatório, conteúdo amorfo eosinofílico e hemácias. Obj. 10X. B - Corte histológico da área de implante no $15^{\circ}$ dia demonstrando neovascularização marcante e infiltrado mononuclear. Obj. 40X.
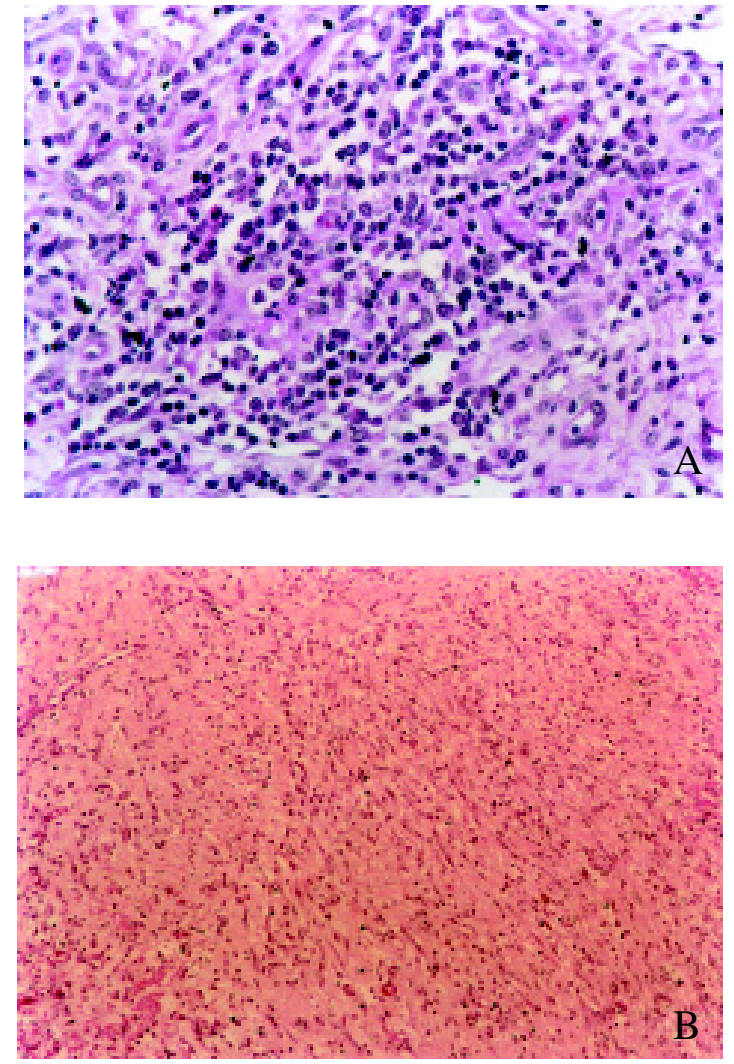

Figura 3.A - Infiltrado inflamatório rico em macrófagos e linfócitos na área de implante no $30^{\circ}$ dia pós-implantação. Obj. 40X. B - Proliferação de tecido conjuntivo fibroso e infiltrado mononuclear na área de implante no $30^{\circ}$ dia pós-implantação. Obj. $10 \mathrm{X}$.

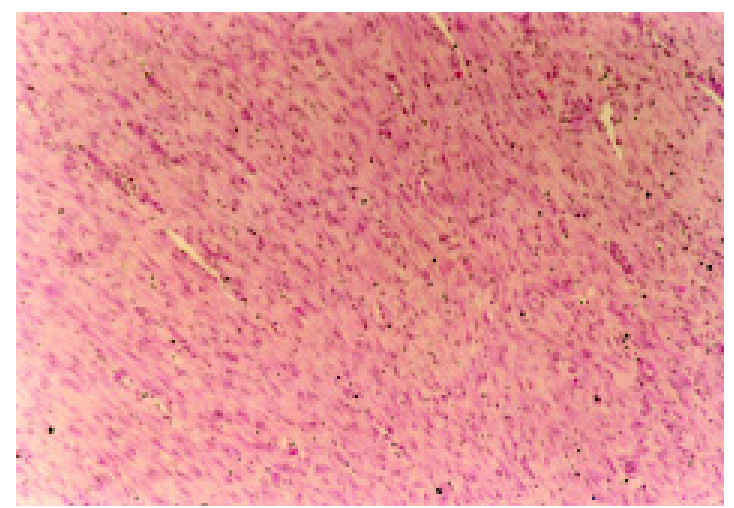

Figura 4. Proliferação marcante de tecido conjuntivo fibroso e infiltrado mononuclear discreto na área de implante no $40^{\circ}$ dia pós-implantação. Obj. 10X. 
Microscopicamente, no $15^{\circ}$ dia pós cirúrgico, observou-se muitos feixes proliferativos, paralelos ou entrelaçados de fibroblastos associados à intensa neovascularização e infiltrado inflamatório rico em macrófagos, contendo ainda linfócitos, plasmócitos e neutrófilos ocasionais, caracterizando tecido de granulação bem formado (Figuras 2A e 2B). Afastando-se da área de implante, havia predominância de fibroblastos, macrófagos e bandas de colágeno. Além disso, notou-se em associação ao implante, feixes de fibrina entremeados por conteúdo amorfo e finamente eosinofílico, neutrófilos e hemácias. Conforme já visualizado na avaliação macroscópica, o tecido conjuntivo proliferativo infiltrava-se na musculatura estriada adjacente.

No $30^{\circ}$ dia após a cirurgia, o tecido vizinho ao implante apresentava feixes paralelos ou entrelaçados de fibras conjuntivas associadas à discreta neovascularização e infiltração marcante de macrófagos. Verificouse pequena quantidade de eosinófilos e neutrófilos de permeio (Figuras 3A e 3B). Havia infiltração do tecido fibroso para o tecido muscular estriado adjacente.

No $40^{\circ}$ dia evidenciaram-se características microscópicas semelhantes as observadas aos 30 dias, entretanto vasos neoformados na área encontravam-se em menor quantidade (Figura 4). Notou-se diminuição discreta e gradativa do infiltrado inflamatório da $1^{\mathrm{a}}$ até a $3^{\mathrm{a}}$ amostra.

\section{DISCUSSÃO}

A técnica de implantação da membrana de látex, poliamida e polilisina a $0,1 \%$ demonstrou ser de fácil execução, sendo o material facilmente manipulável, de alta resistência e elasticidade, não necessitando de conservação. Não observou-se dilaceração do material implantado no momento da aplicação dos pontos, demonstrando boa resistência à tração, conforme observado por outros autores $[8,19]$. Durante o período de avaliação, a membrana manteve sua forma original, diferente da dura-máter humana que no reparo de hérnias abdominais em ratos demonstrou perda do formato tradicional [5].

Nos primeiros 15 dias após a implantação da membrana em estudo, poucas alterações macroscópicas significativas foram notadas na área da implantação, em todos os animais. Edema de discreta intensidade foi a principal complicação evidenciada. Outras investigações também apontam essa alteração inflamatória como a principal complicação pós-cirúrgica quando o centro tendíneo diafragmático homólogo é utilizado na hernioplastia de bovinos [13,14]. Alterações de maior magnitude foram observadas apenas nos animais submetidos à biópsia. Provavelmente, essa reintervenção cirúrgica com intervalo de tempo relativamente curto e a ausência de total cicatrização da região contribuíram para as deiscências de feridas e lesões de caráter inflamatório evidenciadas.

A membrana de látex, poliamida e polilisina a $0,1 \%$ já foi empregada no reparo de lesões parciais do esôfago cervical de cães, com excelente resultado clínico, não sendo observado nenhum caso de infecção ou fistulação [8]. De igual forma, os resultados clínicos obtidos no presente estudo encontram-se respaldados em outros estudos [6], sendo descrita a atoxicidade das membranas de látex, poliamida e polilisina a $0,1 \%$, bem como sua biocompatibilidade, suscitando menores possibilidades de rejeição deste material como bioimplante.

Por ocasião das reintervenções cirúrgicas para colheita de amostra para histolopatologia, foi observado exuberância de tecido conjuntivo fibroso associado ao implante, o que, provavelmente, serviu de sustentação para a membrana, auxiliando na reconstituição da parede abdominal na região do anel herniário. A falta de incorporação do material compósito pelos tecidos do animal no sítio de implantação também foi mencionada por outros autores, onde o implante serviu apenas como arcabouço para a neoformação tecidual $[8,19]$. Segundo essas investigações, os tecidos neoformados possuem a mesma característica do tecido original, com algumas particularidades, no que diz respeito ao tamanho da fibras musculares neoformadas.

As alterações histológicas evidenciadas nos três períodos de avaliação são compatíveis com tecido de granulação com redução gradativa da intensidade de polimorfonucleares e de neovascularização nas adjacências do implante. Dados semelhantes foram obtidos no reparo de hérnias abdominais em rato utilizando dura-máter humana, malha de polipropileno e enxerto cutâneo autólogo [5]. Os achados microscópicos do presente estudo não indicaram reações de alergia e/ou de rejeição do tecido animal ao implante. Apesar de tratar-se de material compósito não-absorvível, não foi observada reação inflamatória tipo corpo estranho ou demais complicações com a utilização da membrana de látex, poliamida e polilisina a $0,1 \%$, possivelmente porque o material possui baixa antigenicidade. Esse mesmo implante também não demonstrou 
rejeição no reparo de lesões parciais do esôfago cervical de cães, sendo notado reepitelização satisfatória e neoformação das fibras musculares [9]. Materiais implantados de natureza sintética podem incitar resposta inflamatória tipo corpo estranho, conforme observado com as malhas de poliester [12] e de marlex [10] no reparo de falhas da parede abdominal em ratos. Infecções, eliminação do material e recidivas foram descritas com a utilização da tela de marlex na correção de hérnias abdominais [23].

\section{CONCLUSÕES}

Com base nas avaliações clínicas e histopatológicas notou-se que a membrana de látex, poliami- da e polilisina a $0,1 \%$ apresentou bons resultados na reparação de hérnias umbilicais em bovinos jovens, não acarretando a formação de fistulas, infecções ou rejeição.

Ficou evidente que este compósito garante um bom nível de segurança para sua utilização em hernioplastias, podendo auxiliar em correções cirúrgicas de caráter permanente.

\section{NOTAS INFORMATIVAS}

${ }^{1}$ Dorcipec, Vallée S.A. Montes Claros, MG/Brasil.

${ }^{2}$ Anestésico local Pearson, Pearson Saúde Animal Ltda. São Paulo, SP/Brasil.

${ }^{3}$ Penjet Plus, Clarion Biociência Ltda. Goiânia, GO/Brasil. ${ }^{4}$ Pomada Ungüento Vallée S.A., Montes Claros, MG/Brasil.

\section{REFERÊNCIAS}

1 Bracgialli C.S., Daleck C.R., Alessi A.C. \& Costa Neto J.M. 1998. Implante de cartilagem auricular de bovinos, conservada em glicerina no pavilhão auricular de cães - estudo experimental. In: Anais do $3^{\circ}$ Congresso Brasileiro de Cirurgia e Anestesiologia Veterinária (Belo Horizonte, Brasil). p.81.

2 Depuydt K., Boeckx W. \& D'hoore E. 1998. The pedicled tensor fasciae latae flap as a salvage procedure for in a infected abdominal mesh. Plastic and Reconstructive Surgery. 102: 187-190.

3 Dias Filho F.C., Silva L.A.F. \& Silva O.C. 2001. Relatos de experiências de campo. In: Silva L.A.F., Fioravanti M.C.S., Dias Filho F.C. \& Eurides D. (Eds). Sanidade dos bezerros leiteiros: da concepção ao desmame. Goiânia: Talento Gráfica e Editora, pp.80-87.

4 Eurides D., Silva L.A.F., Rabelo R.E. \& Chaves S.M. 2001. O umbigo e a saúde do bezerro. In: Silva L.A.F., Fioravanti M.C.S., Dias Filho F.C. \& Eurides D. (Eds). Sanidade dos bezerros leiteiros: da concepção ao desmame. Goiânia: Talento Gráfica e Editora, pp.24-34.

5 Kama N.A., Coskun T., Yavuz H., Doganay M., Reis E. \& Zeki A. 1999. Autologous skin graft, human dura mater and polypropylene mesh for the repair of ventral abdominal hernias: an experimental study. European Journal of Surgery. 165: 1080-1085.

6 Lachat J.J., Mrué F., Thomazini J.A., Zborowski A.C., Ceneviva R. \& Coutinho-Netto J. 1997. Morfophological and biochemical studies of the biocompatibility of a membrane manufactured from the natural latex of Hevea brasiliensis. Acta Microscópica. 6: 758-759.

7 Mazzini D.L. \& Mantovani M. 1999. Fechamento da parede abdominal com afastamento parcial das bordas da aponeurose utilizando sobreposição com telas de vicryl ou marlex em ratos. Acta Cirúrgica Brasileira. 14 [serial online]. Disponível em: <http://www.scielo.br/acb.htm>. Acessado em: 16 setembro 2004.

8 Mrué F. 1996. Substituição do esôfago cervical por prótese biossintética de látex. Estudo experimental em cães. 114f. Ribeirão Preto, SP. Dissertação (Mestrado em Medicina) - Programa de Pós-graduação em Clínica Cirúrgica, Universidade de São Paulo.

9 Mrué F. 2000. Neoformação tecidual induzida por biomembrana de látex natural com polilisina. Aplicabilidade na neoformação esofágica e da parede abdominal. Estudo experimental em cães. 112f. Ribeirão Preto, SP. Tese (Doutorado em Medicina) - Programa de Pós-graduação em Clínica Cirúrgica, Universidade de São Paulo.

10 Paulo N.M., Siqueira Junior J.T., Fleury L.F.F., Sant'Ana F.J.F., Oliveira L.F., Lima F.G., Borges A.C. \& Theles T.C. 2004. Látex da seringueira (Hevea brasiliensis) sem polilisina e tela de marlex na reconstrução da parede abdominal de ratos (resultados preliminares). In: Anais do I Congresso de Cirurgia Geral da Zona da Mata Mineira (Juiz de Fora, Brasil). p.91.

11 Prophet E.B., Mills B., Arrigton J.B. \& Sobin L.H. 1992. Laboratory methods in histotechnology. Washington: Armed Forces Institute of Pathology, 275p.

12 Quitzan J.G., Rahal S.C., Rocha N.S. \& Crocci A.J. 2003. Comparação entre pericárdio bovino preservado em glicerina e malha de poliéster no reparo de falhas da parede abdominal em ratos. Acta Cirúrgica Brasileira. 18: 297-301. 
13 Rabelo R.E. 2003. Emprego do centro tendíneo difragmático homólogo conservado em glicerina a $98 \%$ e em glutaraldeído a 4 \% como implante para hernioplastias umbilicais recidivantes em bovinos. 72f. Goiânia, GO. Dissertação (Mestrado em Medicina Veterinária) - Programa de Pós-graduação em Medicina Veterinária, Universidade Federal de Goiás.

14 Rabelo R.E., Paulo N.M., Silva L.A.F., Romani A.F., Viana Filho P.R.L. \& Veríssimo A.C.C. 2002. Uso do centro frênico diafragmático na correção de hérnias umbilicais recidivantes em bovinos. Revista Brasileira de Ciência Veterinária. 9: 269-271.

15 Radostits O.M. 2002. Técnicas de exame clínico. In: Radostits O.M., Mayhew I.G. \& Houston D.M. (Eds). Exame clínico e diagnóstico em veterinária Rio de Janeiro: Guanabara Koogan, pp.42-51.

16 Rebhun W.C. 2000. Doenças do gado leiteiro. São Paulo: Roca, 642p.

17 Richa R.V.R. 1987. Nuestra experiencia en glicerina en el tratamiento de las grandes hernias ventrales. Revista Médica. 19: 109-117.

18 Rings M. 1995. Umbilical hernias, and umbilical abscesses, and urachal fistulas - surgical considerations. Veterinary Clinics of North America: Food Animal Practice. 2: 137-147.

19 Sader S.L., Coutinho Netto J., Barbieri Neto J., Mazzetto S.A.,Alves Júnior P., Vanni J.C. \& Sader A.A. 2000. Substituição parcial do pericárdio de cães por membrana de látex natural. Revista Brasileira de Cirurgia Cardiovascular. 15: $338-344$.

20 Silva L.A.F., Fioravanti M.C.S., Eurides D., Juliano R.S.,Acypreste C.S. \& Borges G.T. 1999. Sobreposição com invaginação das aponeuroses dos músculos abdominais no reparo de hérnias umbilicais em bovinos. Veterinária Notícias. 5: 63-67.

21 Silva L.A.F., Paula Neto J.B., Chiquetto C.E., Fioravanti M.C.S., Eurides D., Borges N.C., Atayde I.B. \& Rabelo R.E. 2000. Herniorrafia umbilical em bovinos e avaliação do pós-operatório. In: IV Congresso Brasileiro de Cirurgia e Anestesiologia Veterinária, (Goiânia, Brasil). Ciência Animal Brasileira. 1 (Suppl.): 126.

22 Smeak D.D. 1998. Hérnias Abdominais. In: Slatter D.H. (Ed). Manual de cirurgia de pequenos animais. 2 ed. São Paulo: Manole, pp.533-558.

23 Voyles C.R., Richardson J.D., Bland K.I., Tobin G.R., Flint L.M. \& Polk H.C. 1981. Emergency abdominal wall reconstruction with polypropylene mesh: Short term benefits versus long-term complications. Annals of Surgery. 194: 219-223. 